\title{
Compressive strength behaviour of sulphur tailings paste backfill: effects of binders and additives
}

\author{
AX Wu University of Science and Technology Beijing, China \\ GZ Jiang University of Science and Technology Beijing, China \\ Y Wang University of Science and Technology Beijing, China \\ YM Wang University of Science and Technology Beijing, China \\ HJ Wang University of Science and Technology Beijing, China \\ C Li University of Science and Technology Beijing, China
}

\begin{abstract}
Aimed at the common later strength failure phenomenon in sulphur tailings cemented paste backfill (CPB), this paper studies loss ratio (Li) of the unconfined compressive strengths (UCS) of CPB, and analyses the effect of binders and additives on the UCS behaviour of CPB samples in the laboratory. In testing, when the sulphur content of tailings was $6.1 \%$ and the main sulphide was pyrite, the L120 of samples using ordinary Portland cement (OPC) as a binder was $47.4 \%$. The sulphate-resistant cement (SRC) increased the UCS of samples for seven days by $84.2 \%$, but the UCS for 14 and 28 days decreased by 13.3 and $43.1 \%$, respectively. Portland composite cement (PCC) can obviously deteriorate the UCS of the samples. As the sodium silicate increased the samples' UCS for seven days, the L28 was also raised. Comparatively, a proper amount of citric acid can reduce $L i$, and after seven days UCS did not decrease when the dosage was $0.5 \%$. The $L 56$ of samples with the binder mixed by OPC and slag was 14.6\%, then the UCS increased gradually, and while continuing to add $0.5 \%$ citric acid the UCS had no loss. These findings demonstrate that changing binder and adding moderate additive can avoid the UCS loss of sulphur tailings CPB.
\end{abstract}

Keywords: strength behaviour, sulphur tailings, binders, additives

\section{Introduction}

Ore processing produces a large quantity of tailings. In order to achieve the management of goaf and better utilisation of tailings, a good option is to fill the tailings into the goaf. In recent years, paste filling has become one of the main developments in filling processes, which has the advantage of reducing the amount of binder, improving the quality of filling and the underground working environment (Wu \& Wang 2015).

Some studies have shown that the sulphide and sulphate contained in tailings have a great influence on the stability and strength of cemented paste backfill (CPB). Ayora et al. (1998) found that when the tailings contains pyrrhotite, the CPB will generate excessive secondary gypsum, ettringite (referred to as AFt) and other expansive phases, resulting in the CPB cracking and its strength decreasing. Kesimal et al. (2004) further showed that sulphide is easily oxidised to sulphate, which reacts with hydration products of cement to produce an expansive phase, resulting in a sulphate attack on the CPB. This expansibility can produce higher internal stress in the CPB, thus damaging the strength of the filled body (Kesimal et al. 2004).

In order to solve the deterioration of strength of CPB containing sulphur tailings, researchers carried out plenty of studies. Wen et al. (2016) carried out the ratio test based on filling material mixed with high-sulphur fine tailings and found that the cement-to-sand ratio and slurry concentration have an obvious effect on the CPB strength. Wang et al. (2014) suggested that the effect of sulphate on CPB can be reduced by increasing the cement-to-sand ratio to 1:4. Ercikdi et al. (2009) have demonstrated the practical importance of binder type or dosage and water-to-cement ratio for the short and long-term mechanical performance of CPB. 
Although scholars from around the world have made some progress in research on the influencing factors of sulphur tailings CPB, the sulphur content of tailings is often more than $10 \%$, and the research on control measures of strength is not sufficient. The paper studies the unconfined compressive strength (UCS) behaviour of sulphur tailings CPB and analyses the influence of binder type and additives on it. Further, some measures are put forward to control the UCS deterioration of CPB.

\section{$2 \quad$ Experimental}

\subsection{Raw materials}

Two tailings were used in the experiments. As described in Table 1, the tailings contain $6.1 \% \mathrm{~S}$ and $10 \% \mathrm{Al}_{2} \mathrm{O}_{3}$. Figure 1 shows that $-20 \mu \mathrm{m}$ fines of tailings account for more than $75 \%$ and the non-uniformity coefficient is greater than five, indicating that tailings gradation is good. Figure 2 shows that the sulphides in tailings exist mainly in the form of pyrite $\left(\mathrm{FeS}_{2}\right)$. The sulphur content of tailings II is $1.25 \%$, equivalent to non-sulphur tailings, as a control group.

Table 1 Chemical element analysis results of tailings I

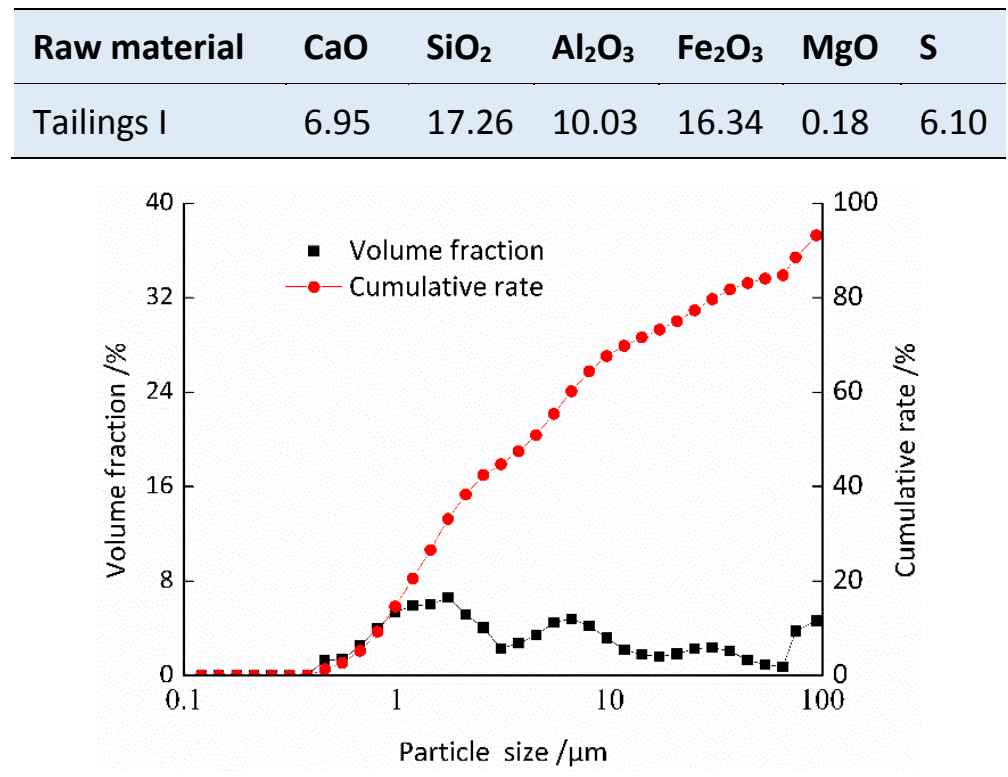

Figure 1 Particle size of tailings I

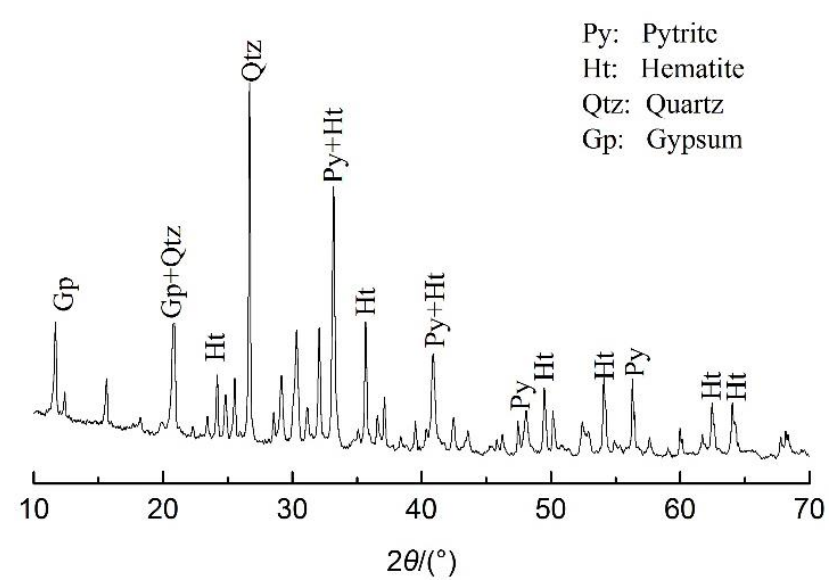

Figure 2 X-ray diffraction pattern of tailings I 
The binders include 425\# type ordinary Portland cement (OPC), 325\# type composite Portland cement (PCC), high sulphate-resistant Portland cement (SRC) and slag. SRC is a hydraulic cementing material prepared by adding gypsum to Portland cement clinker and then grinding this material, which can resist the erosion of high concentrations of sulphate ion. The mineral composition of SRC meets Chinese standard GB 748-2005. PCC is made of Portland cement clinker, $20-50 \%$ of two or more than two kinds of prescribed mixing materials and a proper amount of gypsum to meet Chinese standard GB 175-2007. The proportion of slag particles finer than $30 \mu \mathrm{m}$ is $67.4 \%$, which can improve the hydration property of the slag.

Additives are commercially available, including sodium silicate and citric acid. Sodium silicate can accelerate the development of CPB strength. On the contrary, citric acid can retard the setting velocity of CPB.

\subsection{Test methods}

Firstly, the UCS behaviour of sulphur tailings CPB are studied, and then the influence of binders and additives on the CPB strength behaviour are analysed. Finally, based on the analysis results, the measures controlling UCS deterioration of CPB are put forward. The slurry was mixed using binder, tailings, additive and water in a pot as described in Table 2 . The density and cement-to-sand ratio of paste is $76 \mathrm{wt} \%$ and 1:12, respectively. The paste slurry was then poured into the cube mould of $70.7 \mathrm{~mm}$ in size, which was left to cure under standard conditions (temperature $20 \pm 1^{\circ} \mathrm{C}$, humidity $\geq 90 \%$ ). When the curing times were $7,14,28,56,90$, 120 days, the USC was measured by a USC testing machine with a loading rate of $100-200 \mathrm{~N} / \mathrm{S}$. The UCS is expressed by $R_{i}$, and $i$ represents the curing age. The strength loss calculated from the highest UCS to the UCS at $i$ age is expressed by $L_{i}$. The strength loss rate $L_{i}$ is calculated as follows:

$$
L_{i}=\frac{R_{\max }-R_{i}}{R_{\max }} \times 100 \%
$$

where:

$$
\begin{aligned}
& L_{i}=\text { the strength loss rate at } i \text { days. } \\
& I \quad=7,14,28,56,90 \text { or } 120 . \\
& R_{\max }=\text { the highest UCS during curing age (MPa). } \\
& R_{i} \quad=\text { the UCS at } i \text { days (MPa). }
\end{aligned}
$$

Table 2 Experimental ratio of sulphur tailings CPB

\begin{tabular}{llllll}
\hline Test no. & Types of binders & Slag & Type of tailings & Additive type & Dosage \\
\hline Test 1 & OPC/PCC/SRC & - & I & - & - \\
& OPC & - & II & - & - \\
\multirow{2}{*}{ Test 2} & OPC & - & I & Sodium silicate & $2-6 \%$ \\
& OPC & - & I & Citric acid & $0.3-0.7 \%$ \\
Test 3 & OPC (70\%) & $30 \%$ & I & Citric acid & 0.5 \\
\hline
\end{tabular}

\section{Results and discussion}

\subsection{Effect of binders on UCS}

In test 1, the long-term UCS of the three sulphur tailings CPBs deteriorated. In contrast, the strength of CPB with non-sulphur tailings increased as the curing time extended, and no deterioration occurred (Figure 3). This indicates that when the sulphide content in tailings is $6.1 \%$, it will result in a sulphate attack on the CPB, resulting in deterioration of its late UCS, which is consistent with Bellmann (2006). 


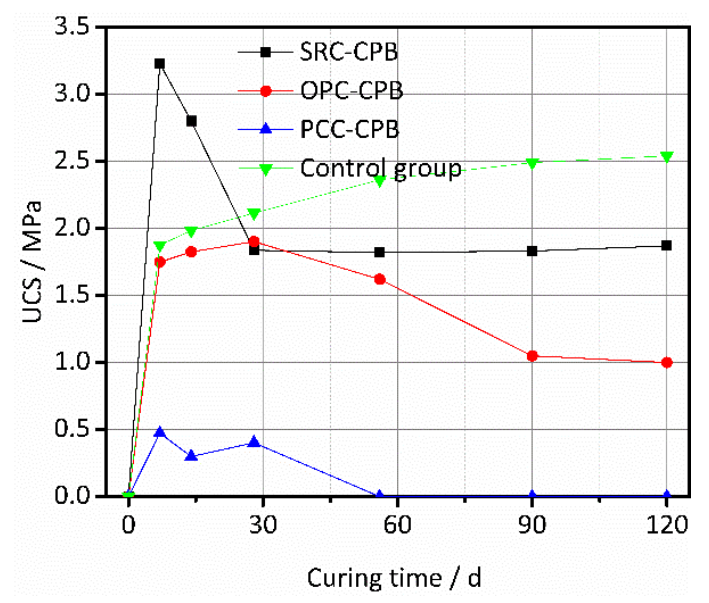

Figure 3 The variation of UCS with time for different binders

When curing for seven days, the UCS growth rate of SRC-CPB that used SRC as a binder was the fastest, followed by OPC-CPB. The UCS growth rate of PCC-CPB was lowest and its UCS for seven days was only $0.47 \mathrm{MPa}$. The UCS of OPC-CPB is 3.7 times higher and 6.8 times higher for SRC-CPB. Therefore, the ideal early strength can be obtained quickly by using SRC.

During the curing period of seven to 28 days, the UCS of SRC-CPB dropped significantly, and L28 reached 43.1\%. There was a slight decrease in UCS as well for PCC-CPB. The UCS of OPC-CPB increased steadily, and reached $1.9 \mathrm{MPa}$ at 28 days, which was at the same level as SRC-CPB. It can be seen that the early UCS deterioration of CPB cannot be effectively suppressed by SRC.

During the curing period of 28 to 120 days, the strength of SRC-CPB stopped dropping and stabilised at about 1.8 MPa. At this point, both OPC-CPB and PCC-CPB showed obvious UCS deterioration. As can be seen in Figure 3 , the $L 120$ of OPC-CPB was $47.4 \%$ and the UCS of PCC-CPB decreased rapidly. When the curing age was 56 days, the PCC-CPB expanded and cracked, completely disintegrating (Figure 4).
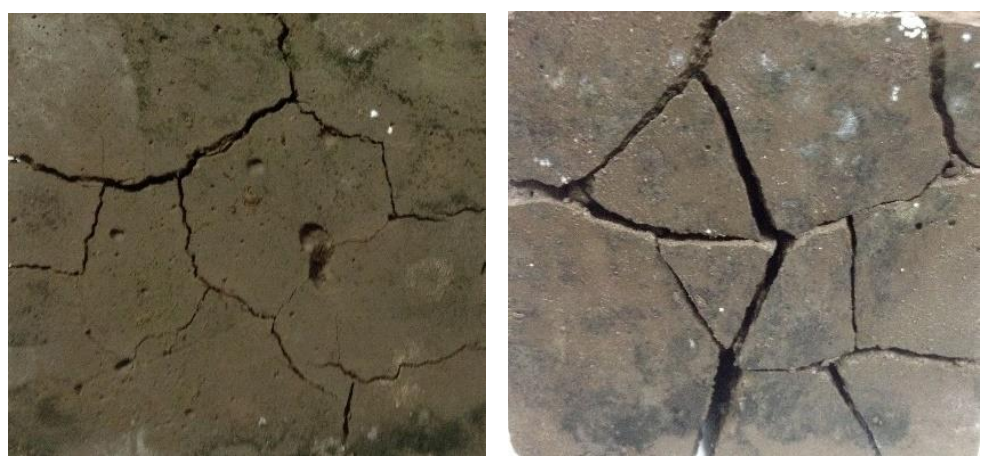

Figure 4 Illustration of disintegration of PCC-CPB after 56 days

The type of Portland cement is critical to the mechanical properties of sulphur tailings CPB. The cost of SRC adopted in the paper is high and cannot effectively restrain the early UCS deterioration of CPB. The reason is that, on the one hand, although SRC can reduce the amount of secondary AFt, the inhibition of secondary gypsum is less. On the other hand, the content of Al in the tailings is relatively high, which is one of the conditions required for the recrystallisation of AFt. In the early stages, SRC fails to control the formation of the expansive phase products effectively, and the sample strength decreases rapidly. However, the amount of $\mathrm{C}-\mathrm{S}-\mathrm{H}$ increases continuously after 28 days, resulting in the stable long-term UCS of the SRC-CPB. PCC can neither obtain reliable early UCS nor guarantee stable long-term UCS of CPB, which is obviously not suitable for the sulphur tailings. This may be due to the large amount of voids in the PCC-CPB, which provide favourable conditions for sulphide oxidation and the formation of the expansion phase. Therefore, OPC is the most suitable binder in this experiment. 


\subsection{Effect of additives on UCS}

When the dosage of sodium silicate was 2, 4 and 6\%, the L120 was 54.7, 56 and 57.5\%, respectively (Figure 5(a)). The sodium silicate, when its dosage was more than $4 \%$, can obviously improve the UCS of CPB at the curing time of seven days, but it had little effect on its long-term UCS. Sodium silicate can increase the early UCS of CPB, but can also aggravate the deterioration of the long-term UCS. The early UCS showed a positive correlation with the UCS deterioration of OPC-CPB.

When the dosage of citric acid was $0.3,0.5$ and $0.7 \%$, the $\mathrm{L} 120$ was $38.2,23.0$ and $17.1 \%$, respectively (Figure 5(b)). L120 decreased with the increase of the additive dosage, indicating that citric acid can reduce the UCS deterioration caused by the expansion phase. When the dosage of citric acid was less than $0.5 \%$, the UCS of CPB at seven days did not decrease with its increase until it was $0.7 \%$, when L120 of CPB decreased further. It can be predicted that if the dosage of citric acid was too high, the internal structure of CPB would be loose and the UCS deterioration would increase. The results may be similar to that of PCC-CPB (Figure 3).
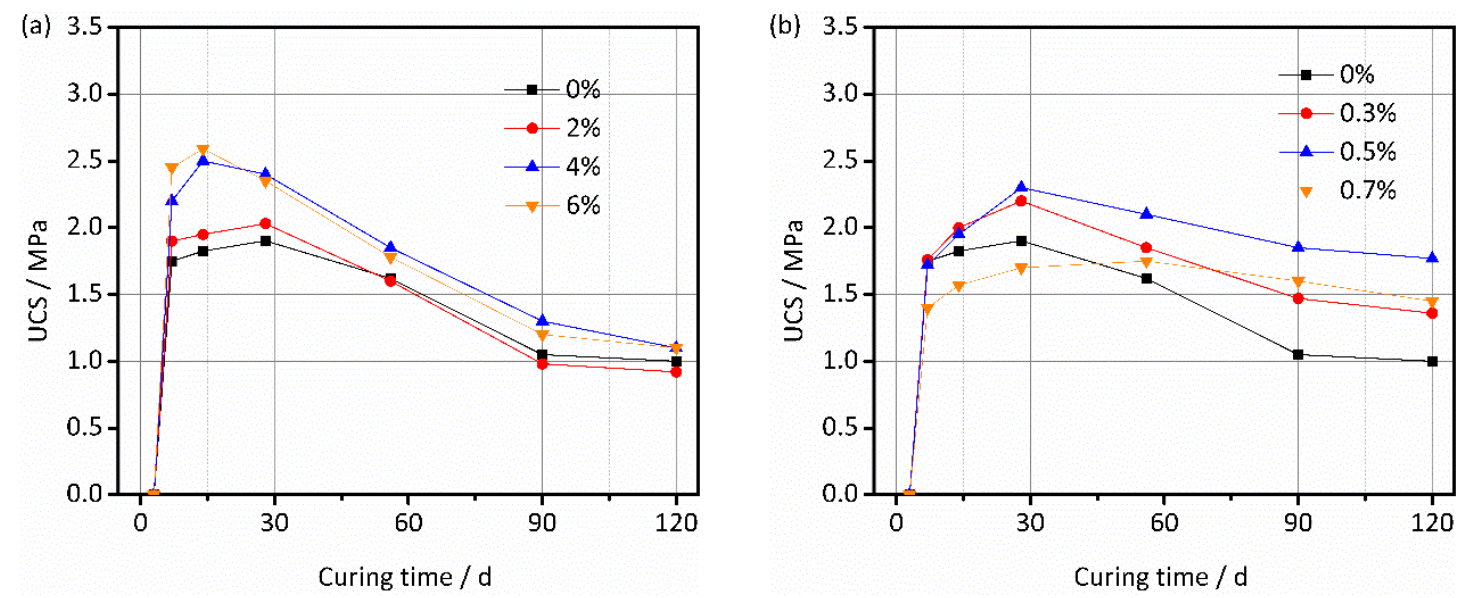

Figure 5 The variation of UCS with time for (a) Sodium silicate; and, (b) Citric acid

Unlike the binder, the additives mainly regulate UCS by affecting the CPB internal porosity. Sodium silicate can increase the compactness of CPB structure, when the secondary expansion products will exert the 'wedging effect' on it, so that the microstructure of CPB is subjected to tensile stresses and cracking, which further increases the CPB strength loss. The UCS of SRC-CPB is high at seven days, and then decreases rapidly. It may be attributed to this wedging effect. The moderate citric acid delays the setting of CPB and at the same time, improves the CPB pore structure development and weakens the wedge effect. The results show that $0.5 \%$ of citric acid is most beneficial to minimise the UCS loss of sulphur tailings CPB.

\subsection{Mechanism analysis of CPB UCS deterioration}

Under certain oxygen and humidity conditions, pyrite is oxidised, leading to the formation of acids and sulphates (Equation 2). The oxidation products further react with $\mathrm{C} 3 \mathrm{~A}$ and $\mathrm{Ca}(\mathrm{OH})_{2}$ to form secondary AFt and gypsum (Equations 3 and 4), the expansion volume of which is 120 and 140\%, respectively (Ercikdi et al. 2009; Yang 2003; Xiao et al. 2006). In addition, the acid formed during the oxidation process will reduce the $\mathrm{pH}$ value of $\mathrm{CPB}$, leading to the decalcification of the $\mathrm{C}-\mathrm{S}-\mathrm{H}$ gel and the reduction of hydration products, which could be why the UCS of CPB decreases (He et al. 2011). The expansion products cause great internal stress in CPB, probably producing microcracks, resulting in a decrease of the later UCS of CPB.

$$
\begin{gathered}
4 \mathrm{FeS}_{2}+15 \mathrm{O}_{2}+8 \mathrm{H}_{2} \mathrm{O} \rightarrow 2 \mathrm{Fe}_{2} \mathrm{O}_{3}+8 \mathrm{SO}_{4}^{2-}+16 \mathrm{H}^{+} \\
3 \mathrm{CaO} \cdot \mathrm{Al}_{2} \mathrm{O}_{3}+3 \mathrm{CaSO}_{4} \cdot 2 \mathrm{H}_{2} \mathrm{O}+30 \mathrm{H}_{2} \mathrm{O} \rightarrow 3 \mathrm{CaO} \cdot \mathrm{Al}_{2} \mathrm{O}_{3} \cdot 3 \mathrm{CaSO}_{4} \cdot 32 \mathrm{H}_{2} \mathrm{O} \\
\mathrm{Ca}(\mathrm{OH})_{2}+\mathrm{SO}_{4}^{2-}+2 \mathrm{H}_{2} \mathrm{O} \rightarrow \mathrm{CaSO}_{4} \cdot 2 \mathrm{H}_{2} \mathrm{O}+2 \mathrm{OH}^{-}
\end{gathered}
$$


From the generation conditions of the expansion phase it can be seen that the UCS deterioration control of $\mathrm{CPB}$ may be considered from three aspects. Firstly, secondary AFt should be reduced by decreasing C3A level in binder. Secondly, the cohesion of CPB should be strengthened by increasing the amount of $\mathrm{C}-\mathrm{S}-\mathrm{H}$ produced in the hydration process of the binder. Finally, the porosity and the amount of expansion phase should be balanced by improving the pore structure of CPB to reduce the occurrence of a wedging effect.

\subsection{Control measures for UCS deterioration of CPB}

According to the aforementioned analysis, the UCS deterioration can be reduced by reducing the production of secondary AFt and increasing the content of $\mathrm{C}-\mathrm{S}-\mathrm{H}$ gel. The slag can react with $\mathrm{Ca}(\mathrm{OH})_{2}$ formed during the binder hydration to produce more $\mathrm{C}-\mathrm{S}-\mathrm{H}$ gel, which can reduce the porosity of $\mathrm{CPB}$ and improve the adhesion between the aggregate interfaces. Therefore, it is reasonable to use slag as one of the main components of the binder. In addition, Section 3.2 described that citric acid can reduce the UCS loss of CPB, and can also be used as one of the control measures.

It can be seen from Figure 6 that the CPB UCS first increased and then decreased, with the increase of curing time after adding $30 \%$ of slag, and the L56 was $14.6 \%$. Thereafter, the UCS gradually increased, and L120 was only $2.4 \%$. Based on the actual production, the addition of $30 \%$ slag in binder can be used as an effective measure to control the UCS deterioration. However, from the point of view of solving the UCS deterioration completely, the dosage of $0.5 \%$ citric acid in the OPC-slag was the final step, when the UCS did not decrease.

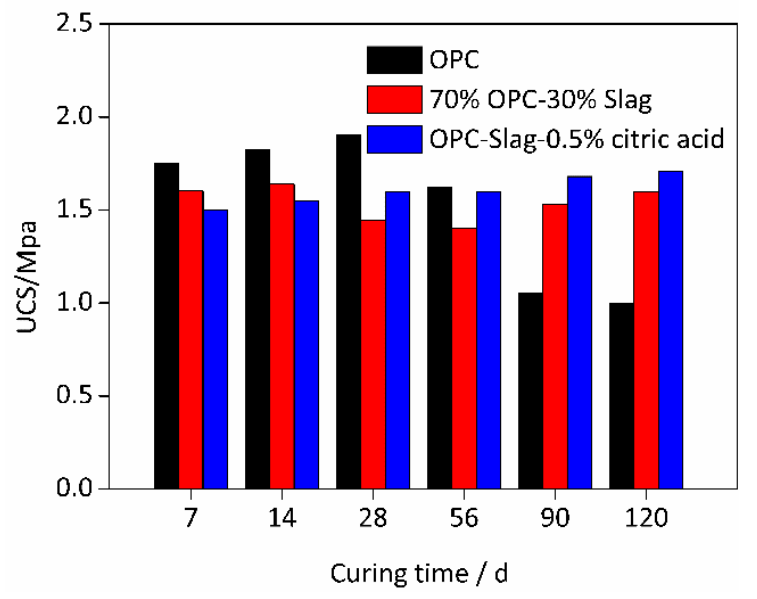

Figure 6 The variation of UCS with time for different control measures

Reducing the expansion phase caused by the replacement of part of OPC by slag and retardation of citric acid, can improve the pore structure of CPB, which may relieve the wedging effect on the early UCS. At the same time, $\mathrm{C}-\mathrm{S}-\mathrm{H}$ gel produced by slag may strengthen the internal cohesion of the structure, which can obviously improve the later UCS of CPB. When the cohesion is greater than the tensile stress produced by the expansion phase, the UCS may stop dropping and begin to rise.

\section{Conclusion}

The option of Portland cement is critical to the UCS behaviour of sulphur tailing CPB, in which the PCC has the worst use effect. The early UCS of SRC-CPB deteriorates and its later UCS is stable, but the cost is high. OPC is the most suitable binder in the test, but the L120 is still up to $47.4 \%$.

After adding sodium silicate, the early UCS of OPC-CPB is positively related to the UCS loss. The citric acid can delay the CPB setting at the same time, and improve the pore structure properly, relieve the wedging effect and reduce the UCS deterioration of CPB.

The slag can react with $\mathrm{Ca}(\mathrm{OH})_{2}$ produced by binders to generate more $\mathrm{C}-\mathrm{S}-\mathrm{H}$ gel, which can improve the later UCS of CPB and reduce the formation of secondary AFt. The UCS of CPB with the binder mixed by OPC-slag is not decreased after adding $0.5 \%$ of citric acid. 


\section{Acknowledgement}

This work is financially supported by the State Key Research Development Program of China (2017YFC0602903), the Fundamental Research Funds for the Central Universities (FRF-TP-17-024A1), the China Postdoctoral Science Foundation (2017M620622) and the University of Science and Technology Beijing.

\section{References}

Ayora, C, Chinchon, S, Aguado, A \& Guirad, F 1998, 'Weathering of iron sulfides and concrete alteration: thermodynamic model and observation in dams from central Pyrenees, Spain', Cement and Concrete Research, vol. 28, no. 4, pp. 591-603.

Bellmann, F, Möser, B \& Stark, J 2006, 'Influence of sulfate solution concentration on the formation of gypsum in sulfate resistance test specimen', Cement and Concrete Research, vol. 36, no. 2, pp. 358-363.

Ercikdi, B, Kesimal, A, Cihangir, F, Deveci, H \& Alp, I 2009, 'Cemented paste backfill of sulphide-rich tailings: importance of binder type and dosage', Cement and Concrete Composites, vol. 31, no. 4, pp. 268-274.

He, Z, Wang, L, Shao, YX \& Cai, XH 2011, 'Effect of decalcification on C-S-H gel microstructure in cement paste', Journal of Building Materials, vol. 14, no. 3, pp. 293-298.

Kesimal, A, Yilmaz, E \& Ercikdi, B 2004, 'Evaluation of paste backfill mixtures consisting of sulphide-rich mill tailings and varying cement contents', Cement and Concrete Research, 2004, vol. 34, no. 10, pp. 1817-1822.

Wang, HY, Zhang, AM \& He, MK 2014, 'Experimental study on unclassified tailing backfill materials proportion and pipeline transportation property with high sulphur and superfine particle', China Mine Engineering, vol. 43, no. 6, pp. 1-4.

Wen, KW, Peng, L, Kang, RH \& Wang, X 2016, 'Experimental study on strength ratio of high sulphur superfine tailings filling material', Mining Technology, no. 4, pp. 40-42.

Wu, AX \& Wang, HJ 2015, Theory and Technology of Metal Ore Paste Filling, Science Press, Beijing, pp. 1-23.

Xiao, J, Deng, DH, Zhang, WN, Zeng, Z \& Tang, XY 2006, 'Formation of gypsum leading to the destruction of cement paste under the external sulphate attacking', Journal of Building Materials, vol. 9, no. 1, pp. 19-23.

Yang, JS 2003, 'Discussion on the action duality of ettringite and it's causing condition in concrete', China Civil Engineering Journal, 2003, vol. 36, no. 2, pp. 100-103. 
